\title{
Assessment of nurses' knowledge and practice regarding postoperative open cholecystectomy patients at Assiut university hospital
}

\author{
Ahmed, W., R ; Essaa, A., E; \& Ahmed, A., M. \\ Medical Surgical Nursing Department, Faculty of Nursing, Assiut University, Assiut, Egypt. \\ General surgery department, Faculty of Medicine, Assiut University, Assiut, Egypt. \\ Medical Surgical Nursing Department, Faculty of Nursing, Assiut University, Assiut, Egypt.
}

\begin{abstract}
:
Cholecystectomy is the surgical removal of the gallbladder. Surgical options include the standard procedure, called laparoscopic cholecystectomy, and an older more invasive procedure, called open cholecystectomy. Approximately 700,000 cholecystectomies are performed annually in the United States. The Aim of the study is to assess nurses' knowledge and practice regarding postoperative open cholecystectomy patients. Descriptive research design was utilized in this study. This study was conducted in the general surgery department at Assiut University Hospital. A convenient sample of 60 nurses was included in this study. Data collected by utilizing the designed interview questionnaire sheet consists of biosocial characteristics of nurses and assessment of nurses' knowledge, observation checklist sheet. The results can be concluded that more than half of nurses $(81.7 \%)$ had poor level of knowledge regarding nursing care of open cholecystectomy. All nurses (100\%) had an inadequate level of practice regarding nursing care for patients post open cholecystectomy. It was found that there was a positive relationship between total knowledge score and total practice score. Conclusion: it can be concluded that, Nurses knowledge and practice regarding nursing care of patient post cholecystectomy are at a poor and inadequate level and need developing nursing care standards to improve nurses` knowledge and practice.
\end{abstract}

\section{Key Words: Cholecystectomy, knowledge, practice, nurse.}

\section{Introduction:}

The gallbladder (GB) is a hollow pear-shaped organ , 7 to $10 \mathrm{~cm}$ length and approximately $4 \mathrm{~cm}$ in diameter and with capacity of 30 to $50 \mathrm{ml}$. It is located on the visceral surface of the liver and can be divided into fundus, body; infundibulum and neck (Smeltzer and Bare, 2007).

The main function of the gall bladder is a reservoir for bile. During fasting resistance to flow through sphincter is high, and the bile excreted by the liver is diverted to the gall bladder. After feeding, the resistance to flow through the sphincter of oddi is reduced, the gall bladder contracts and the bile enters the duodenum. The second main function of the gall bladder is concentration of bile by active absorption of water and, sodium chloride and bicarbonate by the mucous membrane of gall bladder. The third function of the gall bladder is the secretion of the mucous approximately $20 \mathrm{ml}$ is produced per day (Williams, et al, 2008).

Cholecystectomy Most are performed to address symptoms related to biliary colic from cholelithiasis, to treat complications of gallstones e.g., acute cholecystitis, biliary pancreatitis (Hope, 2011). In Assiut, the number of patients who performed cholecystectomy during the period 2010 to 2011 admitted to general surgery department of Assiut university hospital was approximately 380 cases, 327 cases performed open Cholecystectomy and 53 cases performed laparoscopic Cholecystectomy (Assiut University Hospital Records, 2010-2011). Open cholecystectomy (OC) is major surgery that is performed to many cases. Most often, open cholecystectomy is performed because of complications such as perforation, infection, or adhesions from previous surgery, Patients with suspect cancer, very large stones, end stage liver disease, or bleeding disorders may also require open cholecystectomy. Open Cholecystectomy is performed under general anesthesia, which renders the patient unconscious. After the anesthesia is administered, a 5- to 8-inch right or midline incision is made in the abdomen, and the abdominal cavity is opened to expose the gallbladder, the artery to the gallbladder and the cystic duct leading from it are tied off and cut, and the gallbladder is removed (Csikesz, et al, 2009).

Absolute contraindications to proceeding with an open cholecystectomy are few. The only absolute contraindications to the open approach are severe physiologic derangement or cardiopulmonary disease that prohibits general anesthesia. In cases of terminal illness, temporizing procedures such as percutaneous transhepatic cholangiography or percutaneous cholecystostomy should be considered (Hope, 2011). Complications can be classified to complications common to all operations as post anesthesia nausea and vomiting, atelectasis, deep venous thrombosis, wound infection and incisional hernia. And 
complications which are specific to cholecystectomy as hemorrhage, bile duct injury, biliary leakage, jaundice and postcholecystectomy syndrome (Galal, et al, 2007).

Patients need to be monitored closely after the operation. Initially the patient is transferred to the recovery area for a period of monitoring. Patients should stay in recovery room for about an hour or until their condition become stable. The nurse looking after the patient needs to monitor vital signs, pain, the level of post-operative nausea and vomiting (PONV), wound sites and the wound drain (Mitchell ,2007).

It is vital before discharge patients are provided with information about their analgesic regimen, wound care, returning to daily activities and dietary advice. Providing patients with practical discharge advice will improve their confidence in managing their care at home. They should also be warned of the possible complications and what to do if such complications occur (Blay and Donoghue, 2006).

The aim of the study:

The aim of the study is to assess nurses' knowledge and practice for patients post operative open cholecystectomy.

\section{Research questions:}

To fulfill the aim of the study, the following research questions were formulated:

1. What is the current level of nurses' knowledge about open cholecystectomy?

2. What is the current level of practice of nurses regarding care for patients undergoing post operative open cholecystectomy?

\section{Subjects and Methods:}

Research design: Descriptive research design was utilized in this study.

Setting: The study was conducted in the general surgery Department at Assiut University Hospital.

Sample: A convenience sample of all available nurses (60 nurses) working in general surgery department at Assiut University Hospital.

\section{Tools:}

Tool I: Interview questionnaire sheet: it was designed by the researcher based on current national and international literature to assess nurses' knowledge regarding care of cholecystectomy patients and it consists of two parts:

Part (1): Sociodemographic characteristics of nurses: it includes age, gender, marital status, qualification, and years of experience.

Part (2): Assessment of nurses' knowledge: it includes definition cholecystectomy, indications, methods, times of hand washing, warning signs postoperative cholecystectomy, signs and symptoms of chronic cholecystectomy, foods must be avoided postoperative, signs of shock, signs and symptoms of wound infection and postoperative complications.

Tool II: Observation checklist sheet: it was designed by the researcher after reviewing of literature to assess nurses' practice. It was including the following:

Performing hand washing, immediate postoperative nursing care of cholecystectomy patient, assessing and monitoring vital signs (temperature, pulse, respiration and blood pressure), assessing fluid intake and output, performing nasogastric tube care, performing a routine urinary catheter care, care of wound site, wound drain care and instructions before discharge (instructions about comfort and rest, surgical site care, Diet, managing pain and home medications and routine follow up).

\section{Scoring system:}

For interview questionnaire: the total scores of questionnaire was 50grades, each right answer was given one score. Those who obtained less than $50 \%$ (less than 25 degrees) were considered having poor level. While those who obtained $50 \%-70 \%$ (25- 35 degrees) were considered having satisfactory level and more than $70 \%$ (more than 35 degrees) were considered having good level of knowledge.

For observation checklist: The total score was 512 degree, each item in checklist was scored as follow: two degree for each step that done correct and one degree for each step done incorrect and zero for step that not done. Scores more than or equal $60 \%$ (more than or equal 307 degrees) were graded as adequate level of practice. Scores less than 60\% (less than 307) were graded as inadequate level of practice.

\section{Ethical approval:}

An official permission to conduct the study was obtained by the researcher from the head of the general surgery department. Oral consent for voluntary participation was obtained from each nurse and the nature and purpose of the study was described. The researcher emphasized that the participation is voluntary, confidentiality and anonymity of the subjects was assured through coding of all data.

\section{Methods:}

The study was executed on two phases:

Phase (1): preparatory phase:

In this phase, the tools for data collection after reviewing the related literature were developed. Validity of tools was done by 5 experts. By the end of this phase, a pilot study was carried out on $10 \%$ of sample to test the feasibility of the study and applicability of the tools and the time needed to complete the tool was 15 minutes. After pilot study, the tool was used. 
Phase (2): implementation phase:

The interview questionnaire sheet was filled by the researcher while the nurses were on duty; purpose of the study was explained prior to get the questionnaire' questions asked. Each nurse involved in the study was interviewed to answer the questionnaire' questions. Observation checklist for nurses carried out during the morning and afternoon shift.

\section{Results:}

Table (1): Frequency distribution of study sample regarding socio demographic characteristics of nurses.

\begin{tabular}{|l|l|l|}
\hline Socio-demographic characteristics & No. $(\mathbf{n}=\mathbf{6 0})$ & \% \\
\hline Age: (years ) & & \\
\hline$<30$ & 23 & 38.3 \\
\hline $30-<40$ & 19 & 31.7 \\
\hline$\geq 40$ & 18 & 30.0 \\
\hline Mean \pm SD (Range) & $33.03 \pm 8.60(20-55)$ \\
\hline Sex: & \multicolumn{2}{l|}{} \\
\hline Male & 19 & 31.7 \\
\hline Female & 41 & 68.3 \\
\hline Marital status: & & \\
\hline Single & 11 & 18.3 \\
\hline Married & 49 & 81.7 \\
\hline Qualification: & & \\
\hline Nursing diploma & 53 & 88.3 \\
\hline Technical Nursing Institute & 1 & 1.7 \\
\hline Nursing Bachelor & 6 & 10.0 \\
\hline Years of experience: & & \\
\hline < 10 years & 31 & 51.7 \\
\hline 10 - <20 years & 10 & 16.7 \\
\hline$\geq 20$ years & 19 & 31.7 \\
\hline Previous training courses about cholecystectomy: & & \\
\hline Yes & - & - \\
\hline No & 60 & 100.0 \\
\hline
\end{tabular}

Table (2): Distribution of study sample according to the level of knowledge $(\mathrm{N}=60)$.

\begin{tabular}{|l|l|l|}
\hline \multirow{2}{*}{ variable } & $(\mathbf{N}=\mathbf{6 0})$ & $\mathbf{\%}$ \\
\cline { 2 - 3 } & No. & - \\
\hline Good & - & 18.3 \\
\hline Satisfactory & 11 & 81.7 \\
\hline Poor & 49 & \\
\hline
\end{tabular}


Table (3): Relationship between score of nurses' knowledge and socio-demographic characteristics.

\begin{tabular}{|c|c|c|c|}
\hline Socio-demographic characteristics & Mean \pm SD & Range & P-value \\
\hline \multicolumn{3}{|l|}{ Age: (years) } & \multirow{4}{*}{$0.0001 *$} \\
\hline$<30$ & $16.13 \pm 3.18$ & $10-23$ & \\
\hline $30-<40$ & $20.58 \pm 5.11$ & $12-31$ & \\
\hline$\geq 40$ & $22.56 \pm 4.53$ & $14-29$ & \\
\hline \multicolumn{3}{|l|}{ Sex: } & \multirow{3}{*}{0.225} \\
\hline Male & $20.63 \pm 4.36$ & $14-28$ & \\
\hline Female & $18.93 \pm 5.27$ & $10-31$ & \\
\hline \multicolumn{3}{|l|}{ Marital status: } & \multirow{3}{*}{0.061} \\
\hline Single & $16.91 \pm 4.01$ & $10-23$ & \\
\hline Married & $20.04 \pm 5.09$ & $12-31$ & \\
\hline \multicolumn{3}{|l|}{ Qualification: } & \multirow{3}{*}{$0.005 *$} \\
\hline Diploma & $18.81 \pm 4.55$ & $10-31$ & \\
\hline Institute/ Bachelor & $24.43 \pm 6.08$ & $12-30$ & \\
\hline \multicolumn{3}{|l|}{ Years of experience: } & \multirow{4}{*}{$0.0001 *$} \\
\hline$<10$ years & $16.90 \pm 3.94$ & $10-30$ & \\
\hline $10-<20$ & $22.10 \pm 5.20$ & $12-31$ & \\
\hline$\geq 20$ & $22.26 \pm 4.48$ & $14-29$ & \\
\hline
\end{tabular}

Table (4): Distribution of study sample regarding nurses practice $(n=60)$.

\begin{tabular}{|l|l|l|}
\hline \multirow{2}{*}{ variable } & $(\mathbf{N = 6 0 )}$ & $\%$ \\
\cline { 2 - 3 } & No. & 100.0 \\
\hline Inadequate & 60 & - \\
\hline Adequate & - & \\
\hline
\end{tabular}

Table (5): Relationship between score of nurses' practice and socio-demographic characteristics:

\begin{tabular}{|c|c|c|c|}
\hline $\begin{array}{l}\text { Socio-demographic } \\
\text { characteristics }\end{array}$ & Mean \pm SD & Range & P-value \\
\hline \multicolumn{3}{|l|}{ Age: (years) } & \multirow{4}{*}{0.065} \\
\hline$<30$ & $106.17 \pm 13.51$ & $70-126$ & \\
\hline $30-<40$ & $121.63 \pm 39.37$ & $92-247$ & \\
\hline$\geq 40$ & $124.28 \pm 22.05$ & $97-190$ & \\
\hline \multicolumn{3}{|l|}{ Sex: } & \multirow{3}{*}{0.544} \\
\hline Male & $113.32 \pm 15.59$ & $91-144$ & \\
\hline Female & $117.98 \pm 31.45$ & $70-247$ & \\
\hline \multicolumn{3}{|l|}{ Marital status: } & \multirow{3}{*}{0.172} \\
\hline Single & $106.27 \pm 10.53$ & $94-123$ & \\
\hline Married & $118.80 \pm 29.48$ & $70-247$ & \\
\hline \multicolumn{3}{|l|}{ Qualification: } & \multirow{3}{*}{$0.0001 *$} \\
\hline Diploma & $110.11 \pm 15.27$ & $70-144$ & \\
\hline Institute/ Bachelor & $164.86 \pm 47.55$ & $116-247$ & \\
\hline \multicolumn{3}{|l|}{ Years of experience: } & \multirow{4}{*}{0.168} \\
\hline$<10$ years & $110.13 \pm 28.57$ & $70-247$ & \\
\hline $10-<20$ & $125.60 \pm 31.00$ & $93-197$ & \\
\hline$\geq 20$ & $122.11 \pm 21.59$ & $97-190$ & \\
\hline
\end{tabular}


Figure (1): Correlation between score of nurse's knowledge and score of practice.

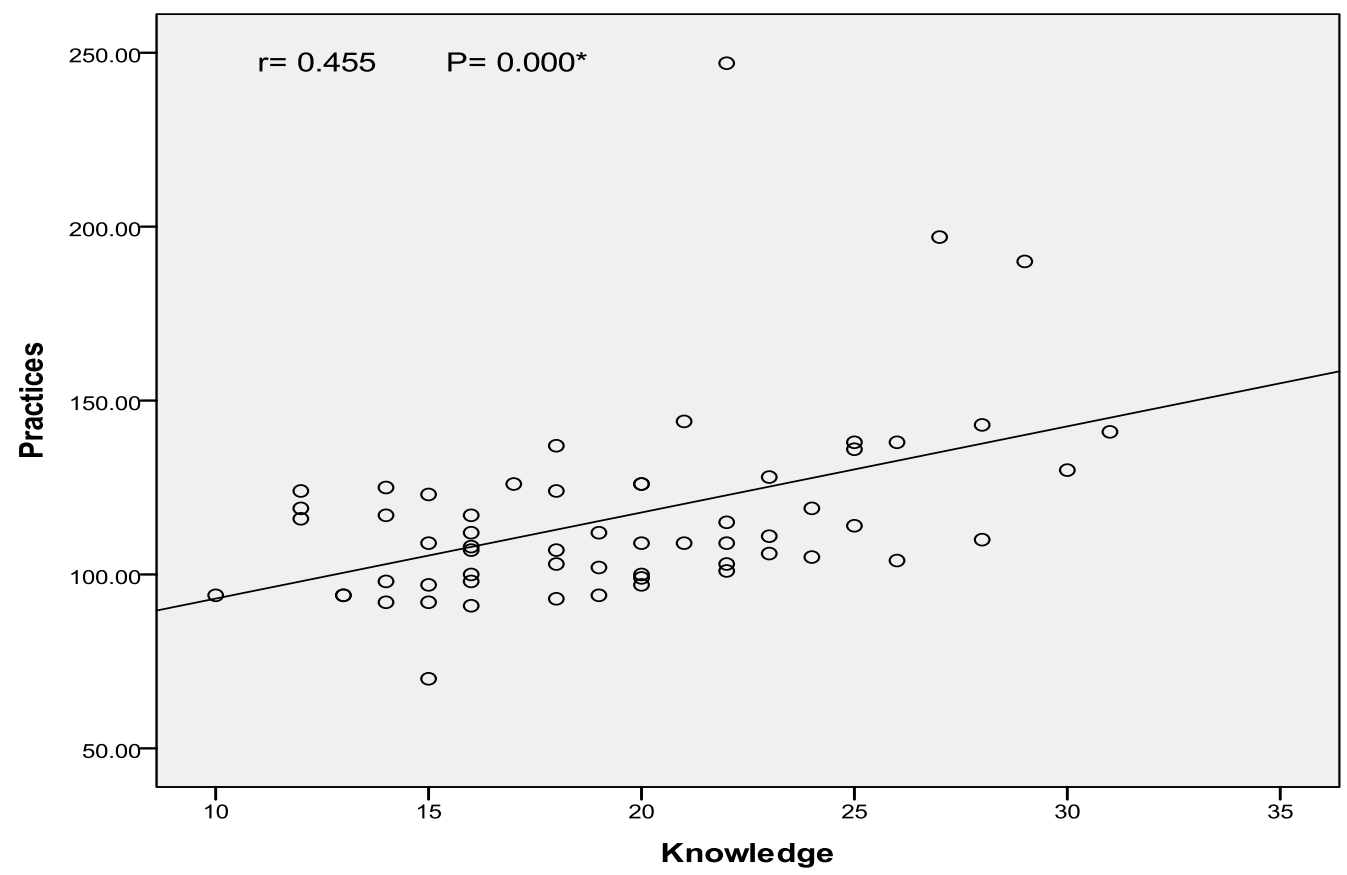

Table (1): This table showed that, the mean age of nurses was $(33.03 \pm 8.60)$, more than half of nurses were females $(68.3 \%)$. As regard to marital status, $(81.7 \%)$ of nurses were married. Also, the table shows that more than half of nurses were diploma nurses $(88.3 \%)$. As regarding to years of experience $<10$ years, $10-<20$ years and $\geq 20$ years were $(51.7$ $\%, 16.7 \%$ and $31.7 \%$ ) respectively. Finally, the table discuss that all nurses (100\%) not attending any previous training program about cholecystectomy.

Table (2): shows that; more than half of nurses $(81.7 \%)$ had poor level of knowledge regarding nursing care of cholecystectomy.

Table (3): The table shows statistical significant difference between score of nurses' knowledge and socio-demographic characteristics in all items except sex and marital status.

Table (4): shows that; all of nurses (100\%) had an inadequate level of practice regarding nursing care for patients post cholecystectomy.

Table (5): The table shows the relation between score of nurses' practice and sociodemographic characteristics, there was no statistical significant difference in all items except qualifications.

Figure (1): The figure shows appositive correlation between score of knowledge and score of practices of nurses regarding postoperative nursing care of cholecystectomy

\section{Discussion:}

The aim of the study is to assess nurses' knowledge and practice for patients care post open cholecystectomy.

Cholecystectomy is the surgical removal of the gallbladder. It is a common treatment of symptomatic gallstones and other gallbladder conditions. Surgical options include the standard procedure, called laparoscopic cholecystectomy, and an older more invasive procedure, called open cholecystectomy (Wikipedia, the free encyclopedia, 2012).

The nurse is responsible and accountable for the quality of nursing care given to patients. The single most important protective strategy for the nurse is to be a knowledgeable and safe practitioner of nursing and to meet the standards of care with all patients (Janice, 2009).

Based on the results of the present study, more than two thirds of nurses were females, married, have nursing diploma, the most of nurses have an experience less than ten years.(Bahza, 2013); is in the same line with the current study findings which revealed that " The majority of nurses were females, married and nursing diploma was the highest proportion, most of them have an experience more than 3 years ".Also, (Mostafa, 2012); revealed that the majority of nurses were females, married, have diploma nursing and the majority of them their experience range from 5 to 10 years. 
In this present study, all the staff nurses did not receive formal training courses in cholecystectomy. In addition, more than two thirds of the nurses had only diploma in nursing in which the content of cholecystectomy was limited in their curriculum. This interpretation is in agreement with (PancorboHidalgo, 2007) who stated that nurses' knowledge was affected by professional education and training. Furthermore, the results revealed that more than half of nurses had poor level of knowledge for cholecystectomy patient's care. This may be related to insufficient scientific courses related to cholecystectomy included in their undergraduate curriculum of nursing education and also this may be attributed to lack of continuous education and inservice training programs.

(Khalil, 2013); was in the same line with the results of the current study which revealed that "data collected before the designed nursing intervention protocol implementation (pre- test) showed unsatisfactory level of knowledge, which reflects the lack in their scientific preparation".

(American nurse association, 2010) believes that education has a significant impact on the knowledge and competencies of the nurse. (Evens, 2006) in another study also discovered that knowledge could be obtained through basic and continuing education, training, personal experience, and in-service training programs.

The current study showed that all nurses had inadequate level of total practice scores in all skills items about care of cholecystectomy patients.(Mohammed,2011); was in the same line with the current study which revealed that "the majority of nurses had unsatisfactory practice level pre implementing teaching protocol". However (Hassan, 2011); was disagree with the current study results which revealed that "the most nurses had adequate level of practice in pre and post implementing designed nursing protocol $(85.7 \%$ and $100 \%)$ respectively.

( Ookalkar, 2009); recommended that educational programs should be organized according to the needs of nurses with continuous evaluation and adopting proper checklists for work monitoring to enhance patient and staff awareness; lead to reduced process errors, reducing overall risks, eventually resulting in effective patient care.

Also, (Youssef, 2007); revealed that an improvement in nurse's practice after the attendance at continuing nursing education sessions. Research findings indicated that continued nursing education programs increase knowledge, practice and can improve attitudes.

(Marquis and Huston, 2009) stressed that education and training are two components of staff development that occur after an employees' indoctrination. The staff knowledge level and capabilities are a major factor in determining the number of staff required to carry out unit goals. The better trained and more competent the staff, the fewer staff required, which in turn saves the organization money and rise reproductively.

The present study shows appositive correlation between score of knowledge and score of practices of nurses' regarding nursing care for patients post cholecystectomy. However, (Ahmed, 2011) revealed that, the results of the study showed that no significant difference between nurses' knowledge and practice scores observed during the pretest. Also, (Thabet, 2013) was disagreeing with the current study which revealed that "There was no positive correlation between nurses' knowledge and practice in pre, immediately and one month post test".

\section{Conclusion:}

Based on the result of the present study, it can be concluded that, Nurses' knowledge regarding cholecystectomy and practice regarding nursing care of patient post cholecystectomy in general surgery department at Assiut University Hospitals are at poor and inadequate level and need nursing care standards to improve nurses` knowledge and practice.

\section{Recommendations:}

Based on the finding of this study, following recommendations were:

1 Continuous education and in-service training programs should be conducted at general surgery department to improve nurses' knowledge and practice.

2 Nurses should be encouraged to read textbooks and periodicals and to attend scientific meeting and conferences.

3 Another study should be done to evaluate the effect of implementing the proposed nursing care standards for patient post cholecystectomy in general surgery department at Assiut University Hospitals.

4 Similar studies on a larger sample acquired from different geographical areas in Egypt should be done to achieve more generalizable results.

\section{References:}

1. Ahmed, R.A (2011): Developing Postoperative care standards for patients who had drainage of chronic subdural hematoma, thesis submitted for partial fulfillment of the requirements of the master degree in adult nursing, Faculty of nursing, Assiut University, Discussion part, 
p.102.

2. American Nurses Association (2010): Scope and Standards of Nursing Practice, Standards of Professional Nursing Practice, 2nd ed., Lippincott Williams \&Wilkins Company, Chap.10 pp.31-39.

3. Assiut University Hospital Records (20102011): Surgical department records, No 3, pp. $354-397$.

4. Bahza, N.M (2013): Developing Nursing Care Standards for Patient with Colostomy at Assiut University Hospital, thesis Submitted for Partial Fulfillment of the Requirements of The Master Degree in Medical Surgical Nursing (Adult Nursing), faculty of nursing. Assiut University, discussion part, pp.57-58.

5. Blay, N. and Donoghue, J. (2006): Source and content of health information for patients undergoing cholecystectomy. International Journal of Nursing Practice. 12, (2): 64-70.

6. Csikesz, N., Ricciardi, R., Tseng, J.F. and Shah, S.A. (2009): Current status of surgical management of acute cholecystitis in the United States, World Journal of Surgery, 32(10): 23-26. From: www.surgeryjournal.co.uk /article/S0263. labstract

7. Evens, R. (2006): A model to describe the relationship between knowledge, skill, and judgment in nursing practice, Nursing Forum; 41(4):150-157.

8. Galal,S. ,Barsoum,M. ,Mohsen,A. ,Fawzy,T. ,and Abdel-halim,S. (2007):Kasr El-Aini introduction to surgery,7th ed., University book center, volume 2, chapter 32 pp.501.

9. Hassan, G.H. (2011): Effect of designed nursing protocol on nurse's knowledge and practice regarding Hemodialysis patients. Submitted for Partial Fulfillment of the Requirements of The Master Degree in Adult Nursing Faculty of Nursing, Assiut University, Results part,p.58

10. Hope,W.W(2011):OpenCholecystectomy.From: www.emedicine.medscape.com/article/1582261indications.

11. Janice, M. (2009): Standards of Parish Nurse Practice. From: allnurses.com/.../standardsparish-nursing-16250.ht.

12. Khalil, Sh. S (2013): Blood transfusion: Impact of implementing a designed nursing intervention protocol to minimize patients complications, thesis submitted for partial fulfillment of the requirements of the master degree in adult nursing, Faculty of nursing, Assiut university, Discussion part ,p.76.

13. Marquis B.L \& Huston C.J (2009): Leader ship roles \& management functions in nursing, 6th ed., Lippincott Williams \&Wilkins company,
Hong Kong,chap.13, p. 371.

14. Mitchell, M. (2007): care of patients undergoing elective surgery. Nursing Standard journal, 21, (30) :48-55.

15. Mohammed, G.T (2011): Infection control: effect of designed teaching protocol on nurses knowledge and practice regarding to hematemsis patients. , thesis submitted for partial fulfillment of the requirements of the master degree in adult nursing, Faculty of nursing, Assiut University, results part, p.67.

16. Mostafa, N.M (2012): Developing standards of post-operative nursing interventions for lower limb amputated patients Submitted for Partial Fulfillment of the Requirements of The Master Degree in Adult Nursing (Medical - Surgical Nursing), Faculty of Nursing, Assiut University, discussion part, pp.75-78.

17. Ookalkar, A. G (2009): "Quality improvement in epileptic process ", International Journal of Quality \& Reliability Management, Vol. 26 (8):817-830.

18. Pancorbo-Hidalgo, P. (2007): Pressure ulcer care in Spain nurses' knowledge and clinical practice, Journal of Advanced Nursing, 58, (4):327-338.

19. Sherwinter, D. (2011): Laparoscopic Cholecystectomy. From: www.emedicine.medscape.com/article/1582292overview).

20. Smeltzer, S.C and Bare, B.G (2007): Brunner \&Suddarth text book of medical-Surgical nursing, 10th ed., Lippincott Williams \& Wilkins, chap.40, p.1124.

21. Thabet,M.A (2013): Effect of a designed nursing protocol on nurses knowledge and practice regarding intravenous therapy, thesis submitted for partial fulfillment of the requirements of the master degree in adult nursing, faculty of nursing, Assiut university, discussion part p.70.

22. Wikipedia, the free encyclopedia (2012): Laparoscopic cholecystectomy. From: www. en.wikipedia.org/wiki/Cholecystectomy.

23. Williams, N.S, Bulstorode, C.J and Connell, P.R (2008): Bailey \& Loves short practice of surgery, 25th ed., Hachette UK. Company, chapter 63, pp.1120-1122.

24. Youssef, S., S., (2007): Micro vascular free tissue transfer surgeries Impact of a designed teaching protocol on nurse's knowledge, practices and patient's outcome. Submitted for partial fulfillment of the requirements of Doctorate Degree in Adult Nursing, Faculty of Nursing, Assiut University, results part, p.76. 